\title{
Potency of Mancozeb Conjugated Silver Nanoparticles Synthesized from Goat, Cow and Buffalo Urine Against Colletotrichum gloeosporioides Causing Anthracnose Disease
}

\author{
S. N. Raghavendra, H. S. Raghu†, C. Chaithra and A. N. Rajeshwara \\ Department of Biochemistry, Kuvempu University, Shankarghatta-577451, Karnataka, India \\ $†$ Corresponding author: H. S. Raghu; hsr1983@gmail.com
}

\begin{abstract}
Nat. Env. \& Poll. Tech. Website: www.neptjournal.com

Received: 27-09-2019

Revised: 17-10-2019

Accepted: 26-11-2019

Key Words:

Anthracnose disease

Colletotrichum gloeosporioides

Mancozeb

Silver nanoparticles
\end{abstract}

\begin{abstract}
Silver nanoparticles of 22-40 nm size were synthesized using goat, cow and buffalo urine. These nanoparticles are conjugated with a fungicide (Mancozeb). The antifungal activity of these conjugated nanoparticles (Mc-AgNPs) was tested against Colletotrichum gloeosporioides which causes anthracnose disease in various fruits and vegetables. This fungus infects during pre and postharvesting seasons causing a significant decrease in the quantity and quality of the product. The fungicide conjugated AgNPs were characterized by UV-Visible, FTIR, SEM and XRD analysis. The synthesis of AgNPs was confirmed by the UV-visible spectroscopy. The shape of AgNPs was found to be spherical. The Mc-AgNPs from goat, cow and buffalo urine exhibited $146.15 \%, 133.33 \%$ and $114.28 \%$ more antifungal activity than the fungicides alone respectively. The results indicate that the Mc-AgNPs from goat urine showed more efficacy than cow and buffalo urine. The fungicideconjugated AgNPs drastically reduce the amount of fungicide to be applied against Colletotrichum gloeosporioides, which in turn reduce the hazardous effect caused by fungicides. Further, these can be tested to control other pathogenic fungi also.
\end{abstract}

\section{INTRODUCTION}

In every facet of nanotechnology, the buzzing of nanotechnology has been flourishing at a remarkable rate in recent decades (Jain et al. 2011). The bionanoparticles can work efficiently as fertilizer, pesticide and fungicide in the field of agriculture and horticulture. The biological products can reduce metal ions to metal nanoparticles. The biological products are ecofriendly, less toxic, cost-effective and also have sacred molecules which enhance the quality and quantity of products in agriculture and horticulture (Govarthanan et al. 2014). The biomaterials like plant extracts, animal secretions and microorganisms can be used to synthesize the AgNPs (Kumar et al. 2009, Ahmad et al. 2003, Shahverdi et al. 2007, Jha et al. 2009, Atul et al. 2008, Lee et al. 2013). The proteins are involved in the reduction and stabilization of nanoparticles (Velmurugan et al. 2011).

The world has a very rich heritage in the domestication of a wide range of livestock. The cow, buffalo and goat are common livestock which are widely reared all over the world. According to $19^{\text {th }}$ livestock census-2012 from Department of Animal Husbandry, Dairying and Fisheries following Ministry of Agriculture, India, the distribution of livestock population was found to be $37.28 \%$ cattle, $21.23 \%$ buffaloes,
$12.17 \%$ sheep, $26.04 \%$ goats and $2.01 \%$ pigs. The population of buffalo is 108.7 million, cow 122.9 million, goat 135.17 million and sheep 65.06 million. The secretions from these livestock have great importance in Ayurveda, Unani and Siddha medicine, which are rich in proteins, lipids, carbohydrates, micronutrients and antioxidants. The cattle like cow and buffalo are treated as sacred in world heritage and the use of the secretions like milk, dung, urine, ghee, buttermilk and curd are widely used.

Goat urine (Ajamutra) is an astringent, sweet with wholesome many beneficial properties as per Ayurveda (Vaibhav et al. 2018). The goat urine has antibacterial and antifungal properties against various pathogens. The Ajamutra has nitrogenous constituents like nitrogen, uric acid, allantoin, hippuric acid, creatine, creatinine and ammonia, and the non-nitrogenous contents like carbonates, bicarbonates, phosphates, sulphates, chlorides, calcium and magnesium (Ferichani 2013). The cow urine (Gomutra) and Ajamutra have great future in modern pharmacology because of their universal availability, cost-effective and many beneficial uses (Hazarika et al. 2018).

Cow urine is nectar with many beneficial potentialities which is capable of removing several ill effects and imbalances in the body during infection. It consists of $95 \%$ water, 
$2.5 \%$ urea, and other $2.5 \%$ is the combination of 24 types of salts, hormones, enzymes, vitamins, minerals and antioxidants (Edwin et al. 2008). It is used as biofertilizer to enrich nutrient contents in soil and biopesticides to kill bacteria, viruses and fungi (Jandaik et al. 2015). Cow urine has a pool of sources like nitrogen, phosphorus, potassium, calcium, magnesium, sulfur, chlorite, iron, silicon, lactose, carbolic acid, urea, aromatic acids, aurum hydroxide, hippuric acid, protein and creatinine. The urea vitamins in urine are A, B, C, D and E and gold acids (Pathak \& Kumar 2003). It also works as a plant hormone to enhance the growth of the plant and correct micronutrient deficiency in plants (Pradhan et al. 2018, Sahu et al. 2016).

Buffalo urine (Mahishamutra) has been in use in Ayurveda and traditional medicines. The contents of Mahishamutra are like that of cow urine but the exception is reduced level of nitrogen and phosphorus content and increased level of solids, urea and uric acid (Gianluca et al. 2014, Shourbagy $\&$ Abdel 1953). The cattle urine also contains the microelements like barium, strontium, copper, lead, zinc, nickel and copper (Raghu 2015). The urine composition of buffaloes varies in their oestrous cycle and gestation period (Barman et al. 2013). The Mahishamutra is used as a medicine in the treatment of oedema, piles, abdominal diseases and also alleviate the loss of appetite (Thakur 2004).

Mango (Magnifera indica L.) belongs to Anacardiaceae family and is the eighth most produced fruit in the world. The global demand for mango is fast-paced because it is a cardinal component of the diet and rich in vitamins and minerals. India produces over 18.7 million tons of mango where it stands number one in production (Felipe 2000). The mango is very eminent due to its wide range of adaptability, high nutritive value, richness in variety and delicious taste.

Anthracnose is a prominent pre and post-harvest disease of many plants including fruits and vegetables. The disease appears in flowers, young fruits, leaves, twigs and stored mature fruits as slightly, black, sunken, irregular shape lesions (Prakash et al. 1997, Fitzell \& Peak 1984, Jefferies et al. 1990). The quiescent infection on immature fruits leads to a reduction of yield to $25-30 \%$ in mango (Abd-Alla \& Wafaa 2010). The disease spreads with rain splash, insects, wind and garden tools. Anthracnose is caused by fungi of genus Colletotrichum. It is commonly called as brown blight (coffee and tea), dieback (citrus), stem canker and anthracnose tear stain (mango) (Sayiprathap et al. 2018, Kamle et al. 2013).

Colletotrichum gloeosporioides is most common disease plant pathogenic fungus in many host plants like citrus, yam, papaya, tomato, mango, coffee and sweet pepper. The life cycle encountered by fungi involves the production of spores on a susceptible host, dispersal of spores, penetration of host tissue, the start of infection process inside the cell, the emergence of lesions, the formation of bristly spores and spreads in various ways. The pathogen has high graving dimension at high humidity and temperature of $20-30^{\circ} \mathrm{C}$ (Davis et al. 1987). The Penzig reported the pathogenic Colletotrichum gloeosporioides. The C. gloeosporioides (Penz.) is ubiquitous species belonging to Ascomycetes family and order Melanovoniales, with cosmopolitan distribution (Kamle \& Pradeep 2016, Ajay Kumar 2014). The pathogen infects either as a parasite (primary disease-causing organism), saprophyte (infect deteriorated plant parts) or endophytic fungi (live inside plant tissue). The optimal growth conditions for C. gloeosporioides are high humidity, the temperature of 25-30 ${ }^{\circ} \mathrm{C}$ and $\mathrm{pH}$ 6-7.

Mancozeb is a non-systemic broad-spectrum protectant fungicide for control of a wide range of disease in agriculture, horticulture and ornamental crops. It is a member of ethylene-bis (dithiocarbamate) (EBDC). In I962, Rohm and Haas signified mancozeb as zinc ion complex of maneb. The most versatile group of an organic fungicide is EBDC fungicide among which mancozeb is most significant in commercial use. The empirical formula is $\left[\mathrm{SCSNHCH} \mathrm{CH}_{2}\right.$ $\mathrm{NHCSSMN}_{\mathrm{x}}(\mathrm{Zn})_{\mathrm{y}}$ (Venugopal \& Sainadh 2016). It is grey to yellow coloured powder with multisite action. Mancoz$\mathrm{eb}$ is a profungicide and breaks down to release ethylene bis-isothiocyanate sulphide (EBIS) on exposure to water, and converted to ethylene bis-isothiocyanate (EBI) on the action of UV light. For control of diseases, mancozeb is sprayed with an interval of 14 days between panicle emergence and fruit set (Gullino et al. 2010, Jigneshkumar et al. 2014).

\section{MATERIALS AND METHODS}

\section{Pathogen Culture}

The spores of fungus Colletotrichum gloeosporioides were cultured using potato dextrose agar (PDA) medium and mango fruit extract agar (MFEA) (Abera et al. 2016) for 6-8 days at $30^{\circ} \mathrm{C}$. The cultural isolate was obtained from infected fruits and vegetables such as mango, papaya and chilly. The spores were harvested in 7-10 mL of sterile double distilled water using inoculation loop in aseptic condition. The cyclomixer was used for spore suspension unification and the spore concentration was found to be $10^{6}$ spores per $\mathrm{mL}$ with the aid of haemocytometer (Abd-Alla \& Wafaa 2010).

\section{Urine Sample Collection}

Urine samples of goat, cow and buffalo were collected from the domestic yard of Santhekadur village, Shimoga district, Karnataka, India. During dawn, around $50-80 \mathrm{~mL}$ of urine sample was collected from healthy livestock in sterile wide- 


\section{X-Ray Diffraction Analysis}

The Scherrer formula was used to calculate the crystallite domain size from the width of XRD peaks, assuming that they are free from non-uniform strains.

$$
\mathrm{D}=0.94 \lambda / \beta \operatorname{Cos} \theta
$$

Where, $\mathrm{D}$ is the average crystallite domain size perpendicular to the reflecting planes, $\lambda$ is the $\mathrm{X}$-ray wavelength, $\theta$ is the full width at half maximum (FWHM), and $\beta$ is the diffraction angle. To eliminate additional instrumental broadening the FWHM was corrected, using the FWHM from a large-grained Si sample. B corrected $=\left(\mathrm{FWHM}^{2}\right.$ sample - FWHM $\left.{ }^{2} \mathrm{si}\right)^{1 / 2}$.

The lyophilized Mancozeb, AgNPs and Mc-AgNPs of different urine samples (goat, cow and buffalo) were coated on the grid and subjected to X-ray diffraction (XRD) measurements (Rigaku Miniflex 600). The analysis was carried out using X-ray diffractometer with an operating voltage of $40 \mathrm{kV}$ and a current of $15 \mathrm{~mA}$.

\section{Fourier Transform Infrared Spectroscopy}

The Mancozeb, AgNPs and Mc-AgNPs of different urine samples (goat, cow and buffalo) were subjected to Fourier transform infrared (FT-IR) spectroscopy (Bruker, USA) to analyze their spectra. The analysis was carried out with potassium bromide $(\mathrm{KBr})$ pellets, recorded in the range of $500-4000 \mathrm{~cm}^{-1}$.

\section{In Vitro Antifungal Activity of AgNPs and Mc-AgNPs}

The antifungal activity of AgNPs and Mc-AgNPs of different urine samples (goat, cow and buffalo) was investigated by well plate method, in vitro along with fungicide Mancozeb as control. The synthesized fungicides Mancozeb, AgNPs and Mc-AgNPs were added to wells made in the solidified potato dextrose agar media or mango fruit extract agar (MFEA) spread with the sporal culture of Colletotrichum gloeosporioides uniformly. The plates were incubated at $30^{\circ} \mathrm{C}$ for $48-72$ hours for the visualization of inhibition zones. The inhibition by fungicide Mancozeb was considered as control.

\section{RESULTS AND DISCUSSION}

\section{UV-Visible Spectroscopy}

The UV-Visible spectroscopy is one of the most widely used techniques for the structural characterization of AgNPs. The absorption band in 350 to $550 \mathrm{~nm}$ region is typical for the AgNPs. The UV-visible spectra showed absorption bands in 350 to $550 \mathrm{~nm}$ region which confirms the formation of AgNPs (Sastry et al. 1997, Henglein 1993, Sastry 1998). In the present study, we found that the biological synthesis mouth containers. After the collection of samples, they were immediately transferred to the laboratory and stored at $4{ }^{\circ} \mathrm{C}$ for further use. The urine samples were confirmed for normal biochemicals parameters (glucose, $\mathrm{pH}$, specific gravity, bilirubin, urobilinogen, ketones) with the aid of reagent dip strips urinanalysis (URS-10 T strips, Mumbai, India). The debris and bacterial contamination in samples were filtered through $0.1 \mu$ membrane filter.

\section{Synthesis of Silver Nanoparticles}

Silver nanoparticles (AgNPs) were synthesized by the biological method using urine samples from goat, cow and buffalo. Double distilled deionized water was used to prepare silver nitrate $\left(\mathrm{AgNO}_{3}\right)$. Different volumes $(5,10,15 \mathrm{~mL}$ of $0.001 \mathrm{M}$ ) of silver nitrate were added dropwise to $50 \mathrm{~mL}$ of pre-chilled urine samples with constant stirring for 4-6 hours. The solution turned to light yellow after the addition of 10 $\mathrm{mL}$ of silver nitrate and to brown when all of the silver nitrate has been added. The stirring was continued even after all the silver nitrate was added. Finally, the colloid breaks down to settled out the particles (Geoprincy et al. 2013).

\section{Synthesis of Mancozeb Conjugated Silver Nanoparticles (Mc-AgNPs)}

The fungicide, Mancozeb $(0.1 \%)$ was mixed with urine samples of goat, cow and buffalo. The mixture was pre-chilled for 20 minutes. Silver nitrate $(0.001 \mathrm{M})$ solution was added dropwise to this mixture with vigorous stirring for about 3 to 5 hours. The solution turned to brown after the addition of 20-25 mL of silver nitrate (Raghavendra et al. 2019).

\section{UV-Visible Spectroscopy}

The optical properties of synthesized silver nanoparticles were determined by UV-Visible spectrometry (Thermoscientific). The UV-Visible absorption spectra of AgNPs and Mc-AgNPs of goat, cow and buffalo were observed in the range $350 \mathrm{~nm}$ to $450 \mathrm{~nm}$.

\section{Scanning Electron Microscopy (SEM) Analysis}

The surface topography and 3D view of the synthesized nanoparticles were analysed in SEM (EVO MA18 with Oxford EDS). The morphological characteristics of AgNPs and Mc-AgNPs from different cattle urine samples (goat, cow and buffalo) were established by SEM. The thin films of the samples were prepared on a carbon-coated copper grid by dropping a very small amount of the sample on the SEM grid and the film was allowed to dry by keeping it under a mercury lamp for 5-7 min and then subjected for SEM analysis with a magnification of $1,00,000 x$. 
of AgNPs and Mc-AgNPs using goat urine sample showed the characteristic absorption peak at $403 \mathrm{~nm}$ and $432 \mathrm{~nm}$ respectively (Fig. 1a and b). The AgNPs and Mc-AgNPs synthesized using Cow urine sample showed the characteristic peak at $377 \mathrm{~nm}$ and $405 \mathrm{~nm}$ respectively (Fig. 1c and d). And the AgNPs and Mc-AgNPs synthesized using Buffalo urine sample showed the characteristic peak at $392 \mathrm{~nm}$ and
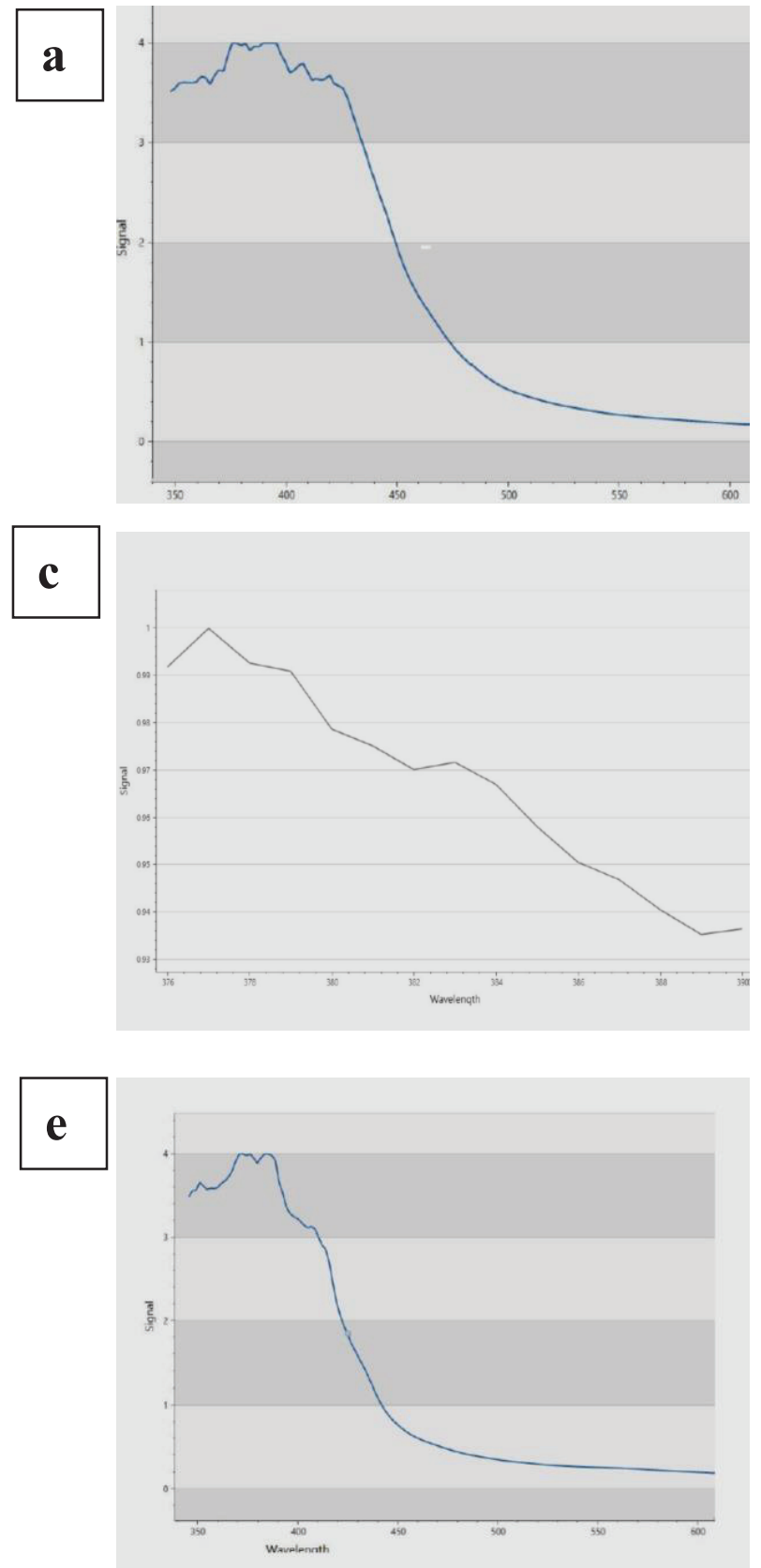

$433 \mathrm{~nm}$ respectively (Fig. 1e and f).

\section{Scanning Electron Microscopy (SEM) Analysis}

Microscopic surface features including morphology and particle size of synthesized AgNPs and fungicide conjugated AgNPs were assessed by SEM analysis. The AgNPs and Mc-AgNPs synthesized using goat urine sample were found
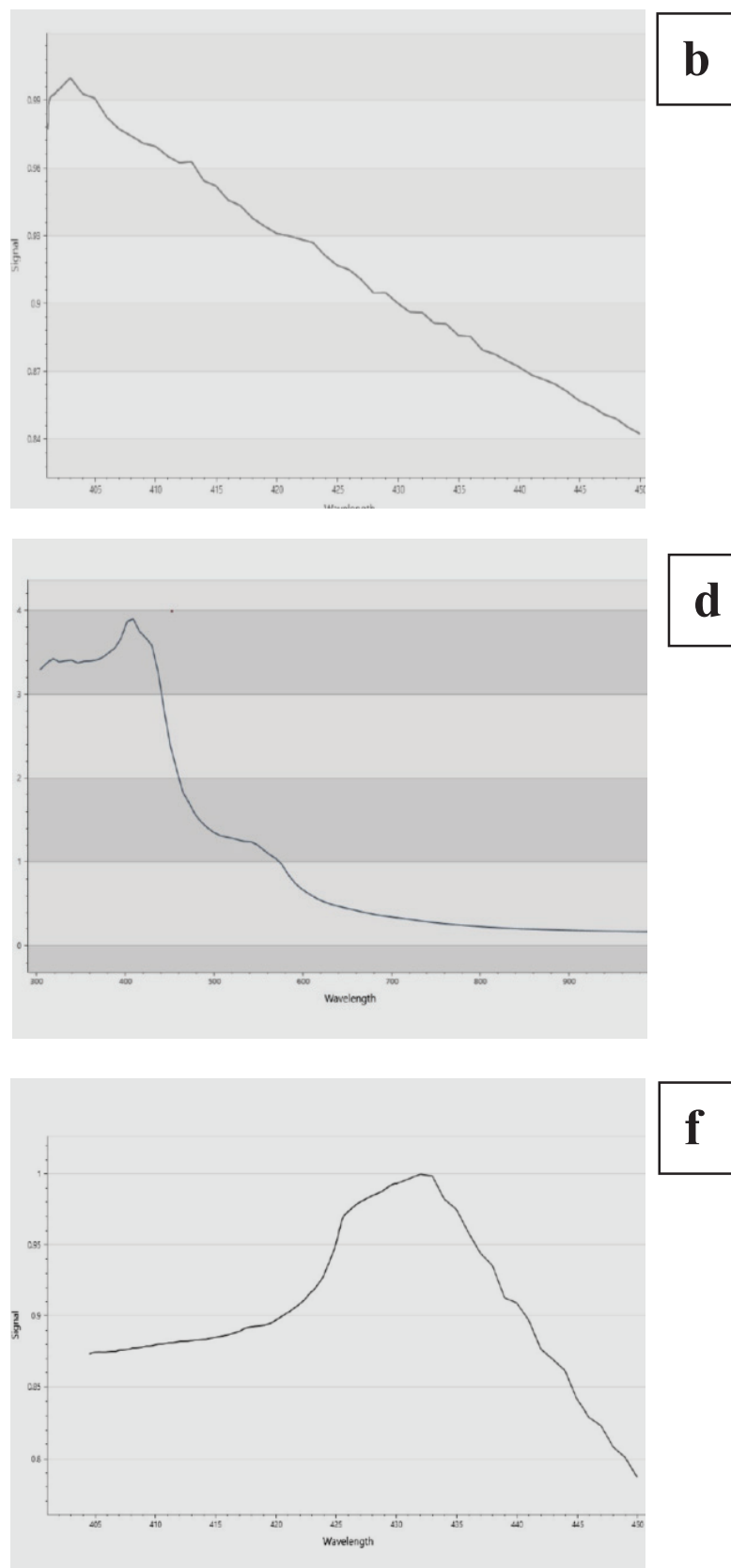

Fig. 1: UV-Vis absorption spectra of (a) AgNPs and (b) Mancozeb conjugated AgNPs synthesized from goat urine sample; (c) AgNPs and (d) Mancozeb conjugated AgNPs synthesized from cow urine sample; (e) AgNPs and (f) Mancozeb conjugated AgNPs synthesized from buffalo urine sample. 
to be spherical with a diameter ranging from 22 to $28 \mathrm{~nm}$ and 26 to $32 \mathrm{~nm}$ respectively (Fig. 2a and b). The AgNPs and Mc-AgNPs synthesized from cow urine sample were found to be spherical with a diameter ranging from 26 to $34 \mathrm{~nm}$ and 30 to $36 \mathrm{~nm}$ respectively (Fig. 2c and d). The AgNPs and Mc-AgNPs synthesized using buffalo urine sample were found to be spherical with a diameter ranging from 28 to
$36 \mathrm{~nm}$ and 32 to $40 \mathrm{~nm}$ respectively (Fig. 2e and f). SEM image also confirms that the synthesized nanoparticles are well separated with no aggregation.

\section{X-ray Diffraction Analysis}

The Mancozeb and synthesized AgNPs and Mc-AgNPs from different cattle urine samples were subjected to X-ray diffrac-
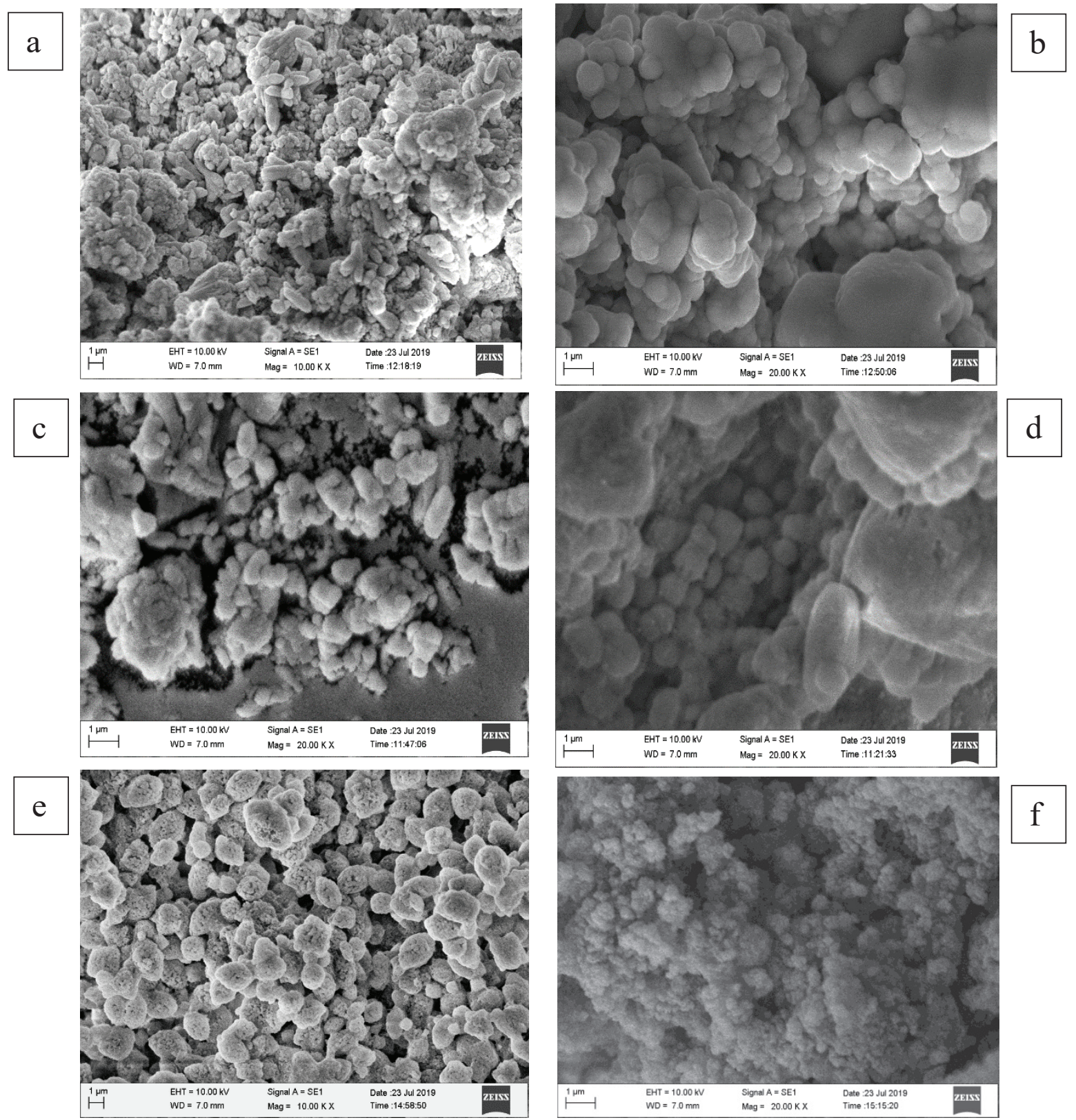

Fig. 2: SEM Images of (a) AgNPs and (b) Mancozeb conjugated AgNPs synthesized from goat urine sample; (c) AgNPs and (d) Mancozeb conjugated AgNPs synthesized from cow urine sample; (e) AgNPs and (f) Mancozeb conjugated AgNPs synthesized from buffalo urine sample. 
tion studies to understand the crystallinity and to establish the average particle size. As shown in Fig. 3a, the XRD pattern of Mancozeb alone showed prominent characteristic peaks of $2 \theta$ at $20.15^{\circ}, 29.64^{\circ}$ and $39.75^{\circ}$ which confirms the presence of Mancozeb (Liang et al. 2010).

The XRD pattern of AgNPs synthesized from goat urine sample (Fig. 3b) has prominent diffraction peaks of the $2 \theta$ values of $30.34^{\circ}, 39.16^{\circ}, 46.82^{\circ}$ and $65.59^{\circ}$ which can be assigned to (111), (200), (220) and (311) planes, respectively, with some minor peaks (Jamdagni et al. 2018). The XRD pattern of Mc-AgNPs synthesized from goat urine sample (Fig. 3c) showed characteristic peaks of $2 \theta$ at $20.65^{\circ}$ and $29.89^{\circ}$ corresponding to Mancozeb and the peaks of $2 \theta$ at $39.56^{\circ}$ and $47.68^{\circ}$ corresponding to AgNPs.

The XRD pattern of AgNPs synthesized from cow urine sample (Fig. 3d) has prominent diffraction peaks of the $2 \theta$

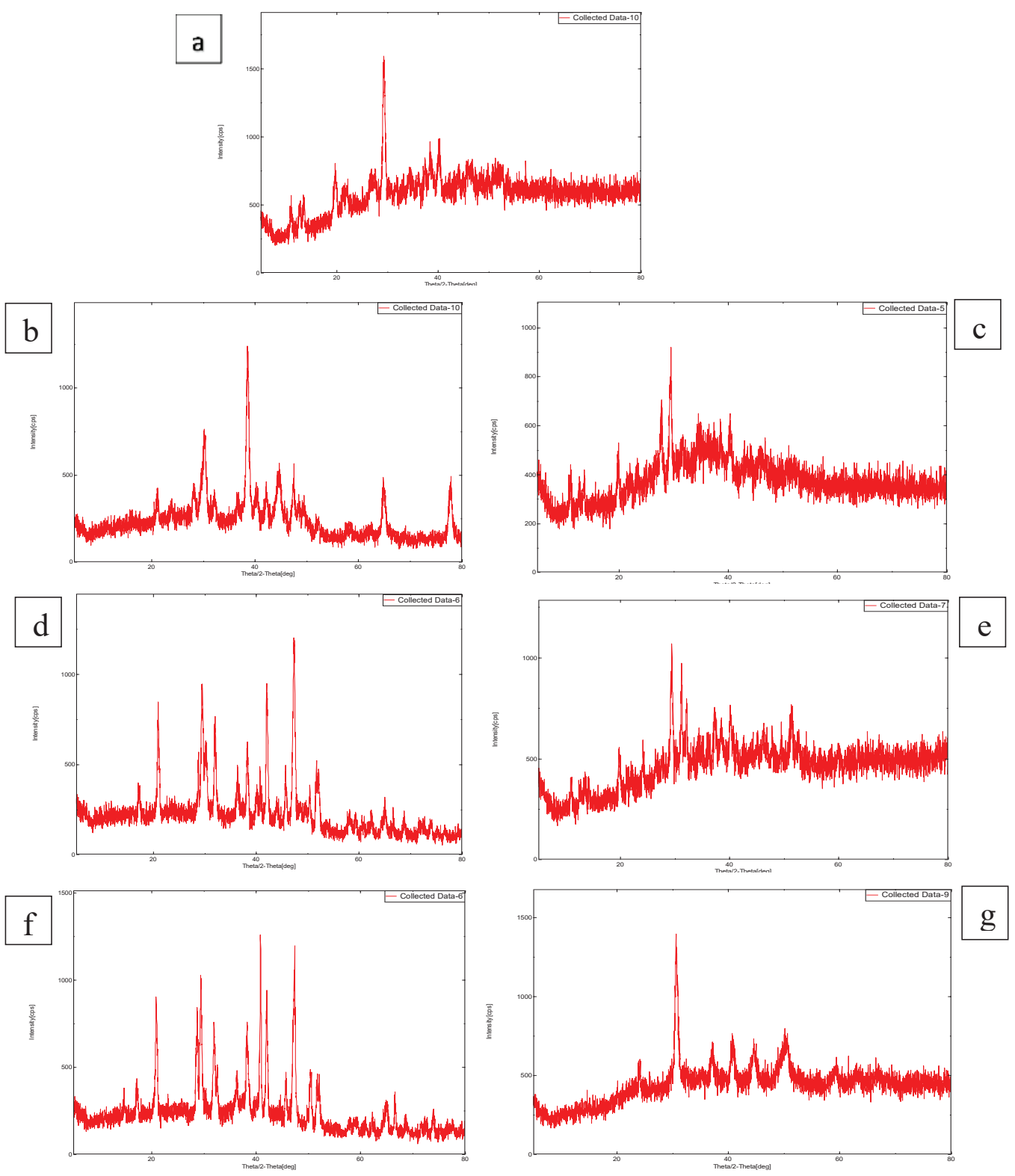

Fig. 3: XRD pattern of (a) Mancozeb; (b) AgNPs synthesized from goat urine sample; (c) Mancozeb conjugated AgNPs synthesized from goat urine sample; (d) AgNPs synthesized from cow urine sample; (e) Mancozeb conjugated AgNPs synthesized from cow urine sample; (f) AgNPs synthesized from buffalo urine sample; (g) Mancozeb conjugated AgNPs synthesized from buffalo urine sample. 
values of $21.22^{\circ}, 30.89^{\circ}, 38.73^{\circ}, 48.59^{\circ}$ and $53.32^{\circ}$ which can be assigned to (111), (200), (220) and (311) planes, respectively, with some minor peaks. The XRD pattern of Mc-AgNPs synthesized from cow urine sample (Fig. 3e) showed characteristic peaks of $2 \theta$ at $20.17^{\circ}$ and $39.86^{\circ}$ corresponding to Mancozeb and the peaks of $2 \theta$ at $30.69^{\circ}$ and $53.62^{\circ}$ corresponding to AgNPs.

The XRD pattern of AgNPs synthesized from buffalo urine sample (Fig. 3f) has prominent diffraction peaks of the $2 \theta$ values of $21.08^{\circ}, 28.86^{\circ}, 32.52^{\circ}, 42.79^{\circ}$ and $47.96^{\circ}$ which can be assigned to (111), (200), (220) and (311) planes, respectively, with some minor peaks. The XRD pattern of Mc-AgNPs synthesized from buffalo urine sample (Fig. 3g) showed characteristic peaks of $2 \theta$ at $39.29^{\circ}$ corresponding to Mancozeb and the peaks of $2 \theta$ at $32.04^{\circ}, 42.09^{\circ}$ and $47.91^{\circ}$ corresponding to AgNPs.

The data confirm that Mancozeb has been successfully adsorbed on the surface of AgNPs.

\section{Fourier Transform Infrared Spectroscopy}

The Mancozeb and synthesized AgNPs and Mc-AgNPs from different cattle urine samples were subjected to Fourier transform infrared spectroscopy studies. The FTIR spectrum of Mancozeb (Fig. 4a) shows characteristic peaks at $3313.46 \mathrm{~cm}^{-1}$ showed the stretching vibrations of -N-H group, $2978.95 \mathrm{~cm}^{-1}$ corresponds to $-\mathrm{C}-\mathrm{H}$ groups and $1286.51 \mathrm{~cm}^{-1}$ Corresponds to -C-N group which confirms the presence of Mancozeb as shown earlier (Bahram et al. 2017).

The FTIR spectra of synthesized AgNPs synthesized from goat urine sample showed various absorption bands for different chemical groups (Fig. 4b) at $3319.62 \mathrm{~cm}^{-1}, 1627.57$ $\mathrm{cm}^{-1}, 1108.46 \mathrm{~cm}^{-1}$ and $874.21 \mathrm{~cm}^{-1}$ (Arment et al. 2005). The FTIR spectrum of Mc-AgNPs synthesized from goat urine sample (Fig. 4c) shows distinct peaks at $3295.13 \mathrm{~cm}^{-1}$ illustrating the stretching vibrations confirms the AgNPs. The peaks at $2976.05 \mathrm{~cm}^{-1}$ and $1282.61 \mathrm{~cm}^{-1}$ establish the adhesion of Mancozeb on the AgNPs.

The FTIR spectra of synthesized AgNPs synthesized from cow urine sample showed various absorption bands for different chemical groups (Fig. 4d) at $3429.14 \mathrm{~cm}^{-1}, 1626.96$ $\mathrm{cm}^{-1}, 1119.04 \mathrm{~cm}^{-1}$ and $714.88 \mathrm{~cm}^{-1}$. The FTIR spectrum of Mc-AgNPs synthesized from cow urine sample (Fig. 4e) shows distinct peaks at $3424.62 \mathrm{~cm}^{-1}$ and $719.99 \mathrm{~cm}^{-1}$ illustrating the stretching vibrations confirms the AgNPs. The peaks at $3302.62 \mathrm{~cm}^{-1}$ and $2970.67 \mathrm{~cm}^{-1}$ establish the adhesion of Mancozeb on the AgNPs.

The FTIR spectra of synthesized AgNPs synthesized from buffalo urine sample showed various absorption bands for different chemical groups (Fig. 4f) at $3438.81 \mathrm{~cm}^{-1}, 1641.78$ $\mathrm{cm}^{-1}, 875.56 \mathrm{~cm}^{-1}$ and $476.34 \mathrm{~cm}^{-1}$. The FTIR spectrum of Mc-AgNPs synthesized from goat buffalo sample (Fig. 4g) shows distinct peaks at $3440.03 \mathrm{~cm}^{-1}, 1640.98 \mathrm{~cm}^{-1} 1,871.42$ $\mathrm{cm}^{-1}$ illustrating the stretching vibrations confirms the AgNPs. The peaks at $2968.74 \mathrm{~cm}^{-1}$ establish the adhesion of Mancozeb on the AgNPs.

\section{Antifungal Activity of AgNPs, Mancozeb and Mc- AgNPs}

The antifungal potential of AgNPs, Mancozeb and Mc-AgNPs was assessed against Colletotrichum gloeosporioides which causes anthracnose disease. The results showed that the inhibition of fungal growth was observed with Mancozeb, AgNPs and Mc-AgNPs of goat urine (Fig. 5). The Mancozeb $(1 \%)$ significantly inhibited with an inhibition zone of diameter $1.3 \mathrm{~cm}$ which is $85.71 \%$ more than the AgNPs which showed the inhibition zone of diameter $0.7 \mathrm{~cm}$. Further, the Mc-AgNPs exhibited the highest growth inhibition of Colletotrichum gloeosporioides $(\sim 146.15 \%)$ more as compared to fungicide Mancozeb alone with an inhibition zone of $3.2 \mathrm{~cm}$.

The inhibition of fungal growth was observed with Mancozeb, AgNPs and Mc-AgNPs of cow urine sample (Fig. 6). The Mancozeb (1\%) significantly inhibited with an inhibition zone of diameter $0.9 \mathrm{~cm}$ which is $80.0 \%$ more than the AgNPs which showed the inhibition zone of diameter $0.5 \mathrm{~cm}$. Further, the Mc-AgNPs exhibited the highest growth inhibition of Colletotrichum gloeosporioides ( 133.33\%) more as compared to fungicide Mancozeb alone with an inhibition zone of $2.1 \mathrm{~cm}$.

The inhibition of fungal growth was observed with Mancozeb, AgNPs and Mc-AgNPs of buffalo urine sample (Fig. 7). The Mancozeb (1\%) significantly inhibited with an inhibition zone of diameter $0.7 \mathrm{~cm}$ which is $75.0 \%$ more than the AgNPs which showed the inhibition zone of diameter 0.4 $\mathrm{cm}$. Further, the Mc-AgNPs exhibited the highest growth inhibition of Colletotrichum gloeosporioides ( 114.28\%) more as compared to fungicide Mancozeb alone with an inhibition zone of $1.5 \mathrm{~cm}$.

These results illustrate that Mc-AgNPs synthesized from goat urine sample have shown $52.38 \%$ more potency against C. gloeosporioides compared to Mc-AgNPs synthesized from cow urine sample and $113.33 \%$ more effective than the Mc-AgNPs synthesized from buffalo urine sample.

\section{CONCLUSIONS}

Currently, there are many chemical fungicides to control plant pathogens which are being used at very high concentrations thus causing environmental pollution. Hence, there is a great need to reduce the use of high concentra- 

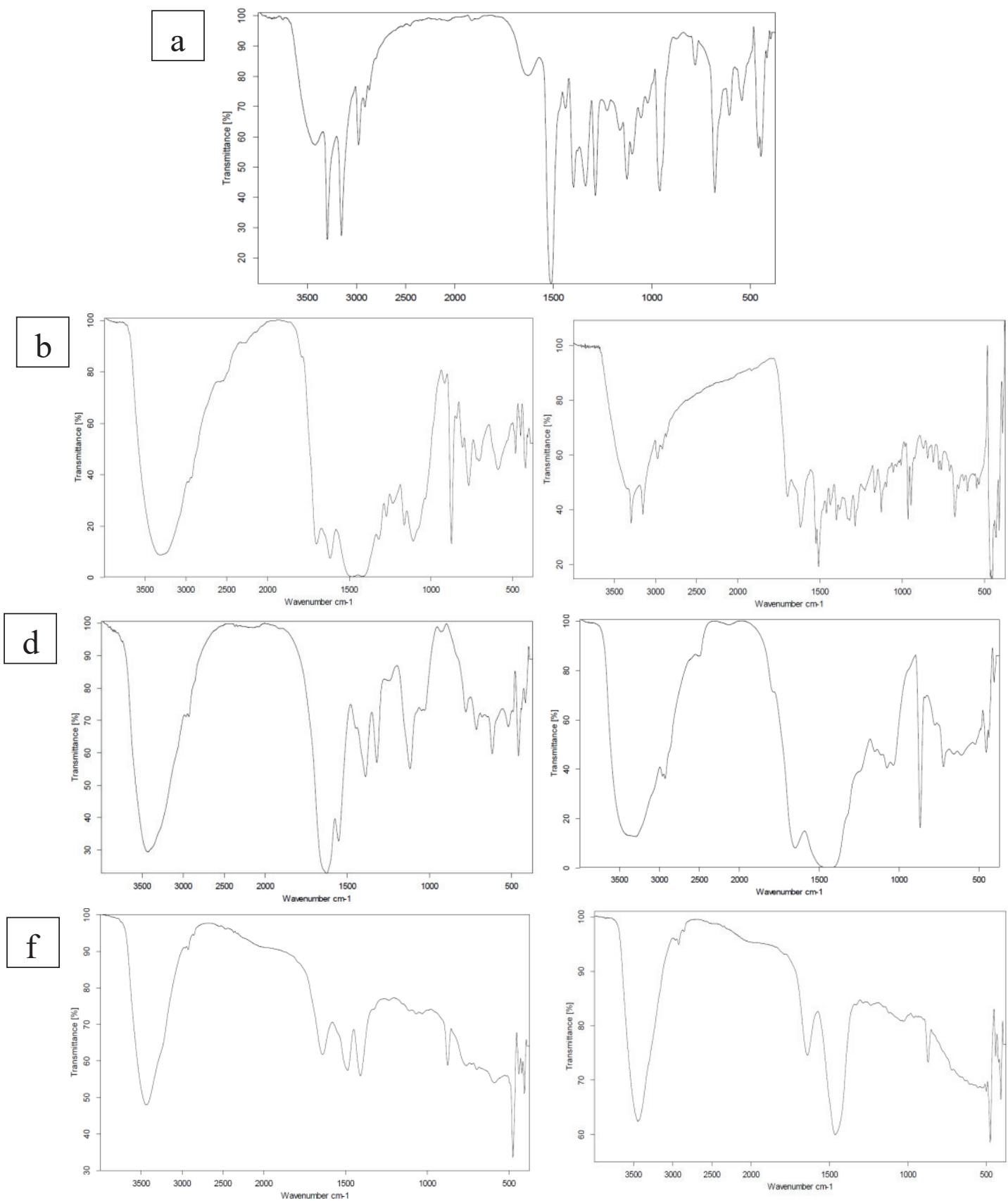

Fig. 4: Fourier transform infrared spectroscopy of (a) Mancozeb. (b) AgNPs synthesized from goat urine sample. (c) Mancozeb conjugated AgNPs synthesized from goat urine sample. (d) AgNPs synthesized from cow urine sample. (e) Mancozeb conjugated AgNPs synthesized from cow urine sample. (f) AgNPs synthesized from buffalo urine sample. (g) Mancozeb conjugated AgNPs synthesized from buffalo urine sample. 


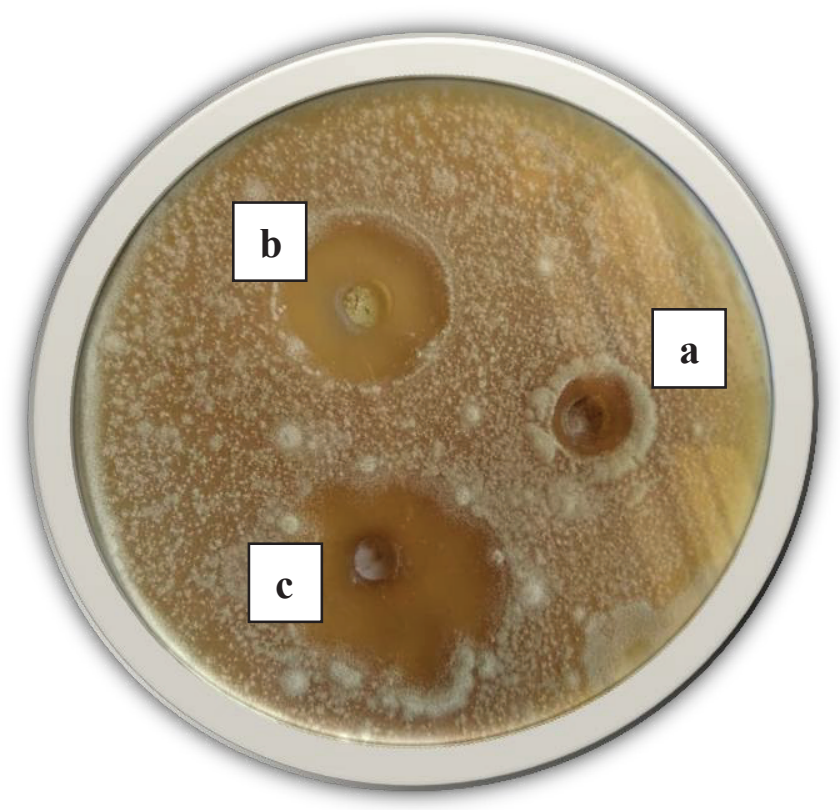

Fig. 5: Antifungal activity of a) AgNPs synthesized from goat urine sample, b) Mancozeb and c) Mancozeb conjugated AgNPs.

tion of fungicides to control plant pathogens which affect several crops worldwide. It has been very well established that AgNPs alone can be an effective means of controlling plant pathogens. However, in the present study, we have synthesized Mc-AgNPs from goat, cow and buffalo urine which greatly enhanced the antifungal potency against
Colletotrichum gloeosporioides at very low concentrations. These can be applied as an economical and environmentally friendly method to control Colletotrichum gloeosporioides which causes anthracnose disease. These Mc-AgNPs could potentially be used in the field to control anthracnose disease caused by $C$. gloeosporioides affecting various plants.



Fig. 6: Antifungal activity of a) AgNPs synthesized from cow urine sample, b) Mancozeb and c) Mancozeb conjugated AgNPs. 


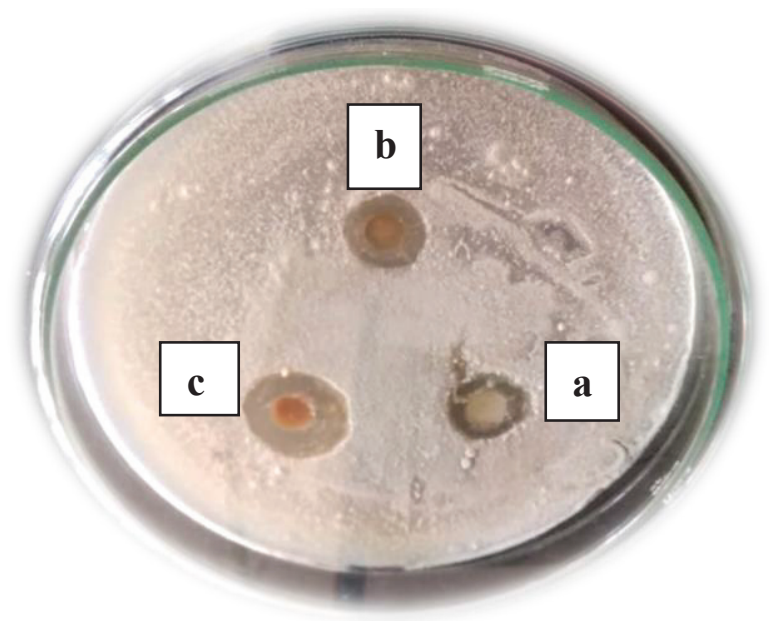

Fig. 7: Antifungal activity of (a) AgNPs synthesized from buffalo urine sample, (b) Mancozeb and (c) Mancozeb conjugated AgNPs.

\section{ACKNOWLEDGEMENTS}

We would like to thank the Department of Biochemistry, Kuvempu University, Shankaraghatta, Karnataka, India for providing the laboratory facility.

\section{REFERENCES}

Abd-Alla, M. A. and Wafaa, M. H. 2010. New safe methods for controlling anthracnose disease of mango (Mangifera indica L.) fruits caused by Colletotrichum gloeosporioides (Penz.). Journal of American Science, 8(8): 361-367.

Abera, A., Lemessa, F. and Adunga, G. 2016. Phenotypic characteristics of colletotrichum species associated with mango (Mangifera indica L.) in Southwest Ethiopia. Food Science and Quality Management, 48: 106-115.

Ahmad, A., Senapati, S., Khan, M. I., Kumar R. and Sastry, M. 2003. Extracellular biosynthesis of monodisperse gold nanoparticles by a novel extremophilic actinomycete, Thermomonospora sp. Langmuir, 19: 3550-3553.

Ajay Kumar, G. 2014. Colletotrichum gloeosporioides: Biology, Pathogenicity and Management in India. J. Plant Physiol. Pathol., 2(2): 2-11.

Arment, S., Garrigues, S. and Guardia, M. 2005. Solid sampling Fourier transform infrared determination of Mancozeb in pesticide formulations. Journal of Talanta, 65: 971-979.

Atul, A. Bharde, Rasesh, Y. Parikh, Maria Baidakova, Samuel Jouen, Baetrice Hannoyer, Toshiaki Enoki, Prasad, B. L. V., Yogesh, S. Shouche, Satish Ogale and Murali Sastry, 2008. Bacteria-mediated precursor-dependent biosynthesis of superparamagnetic iron oxide and iron sulfide nanoparticles. Langmuir, 24: 5787-5794.

Bahram, B. Teimoori, Nikparast, Y., Hojatianfar, M., Akhlaghi, M., Ghorbani, R. and Pourianfar, H. R. 2017. Characterization and antifungal activity of silver nanoparticles biologically synthesised by Amaranthus retroflexus leaf extract. Journal of Experimental Nanoscience, 12: 129-139.

Barman, P., Yadav, M. C., Kumar, H., Meur, S. K. and Ghosh, S. K. 2013. Gas chromatographic-mass spectrometric analysis of chemical volatiles in buffalo (Bubalus bubalis) urine. Theriogenology, 80: 654-658.

Davis, R. D., Irwin, J. A. G., Cameron, D. F. and. Shepherd, R. K. 1987. Epidemiological studies on the anthracnose diseases of Stylosanthes caused by $C$. gloeosporioides in North Queensland and pathogenic specialization within the natural fungal populations. Australian Journal of Agriculture Research, 38: 1019-1032.

Felipe, L. Arauz, 2000. Mango anthracnose: Economic impact and current options for integrated management. Plant Disease, 84(6): 600-611.

Ferichani, M. 2013. The potential Ettawa goat manure and urine management to support the productive and sustainable farming. Journal of Crop and Weed, 9(2): 76-80.

Fitzell, R.D. and Peak, C.M. 1984. The epidemiology of anthracnose disease of mango: Inoculum sources, spore production and dispersal. Ann Appl Biol., 104: 53-59.

Geoprincy, G., Vidhya Sri, B. N., Poonguzhali, U., Nagendra, N. Gandhi and Renganathan, S. 2013. A review on green synthesis of silver nanoparticles. Asian J. Pharm. Clin. Res., 6 (1): 8-12.

Govarthanan, M., Selvankumar, T., Manoharan, K., Rathika, R., Shanthi, K., Lee, K.J., Cho, M., Kamala-Kannan, S. and Oh, B.T. 2014. Biosynthesis and characterization of silver nanoparticles using panchakavya, an Indian traditional farming formulating agent. International Journal of Nanomedicine, 9: 1593-1599.

Gullino, M.L., Tinivella, F., Garibaldi, A., Kemmitt, G.M., Bacci, L. and Sheppard, B. 2010. Mancozeb past, present, and future. Plant Disease, 94(9): 1076-1087.

Hazarika, S., Das, S., Sarma, H. and Sharma, H.K. 2018. Application of cow and goat urine in traditional systems of medicines: A brief review. International Journal of Pharmaceutical and Biological Archives, 9(4): 197-203.

Henglein, A. 1993. Physicochemical properties of small metal particles in solution: Microelectrode reactions, chemisorption, composite metal nanoparticles, and the atom-to- metal transition. Phys. Chem. B, 97: 5457-5471.

Jain, S., Uchegbu, I.F., Betageri, G. and Pastorin, G. 2011. Nanotechnology in advanced drug delivery. Journal of Drug Delivery, 2011: 2.

Jamdagni, P., Rana, J.S. and Khatri, P. 2018. Comparative study of antifungal effect of green and chemically synthesized silver nanoparticles in combination with carbendazim, Mancozeb, and thiram. Advances in Animal Biotechnology and its Applications, 12(8): 1102-1107.

Jandaik, S., Thakur, P. and Kumar, V. 2015. Efficacy of cow urine as plant growth enhancer and antifungal agent. Advances in Agriculture, 2015: 1-7.

Jarald, E., Edwin, S., Tiwari, V., Garg, R. and Toppo, E. 2008. Antioxidant and antimicrobial activities of cow urine. Global Journal of Pharma- 
cology, 2 (2): 20-22.

Jefferies, P., Dodd, J. C., Jeger, M. J. and Plumbley, R. A. 1990. The biology and control of Colletotrichum species on tropical fruit crops. Plant Pathol., 39: 343-366.

Jha, A. K. and Prasad, K. 2009. A green low-cost biosynthesis of $\mathrm{Sb}_{2} \mathrm{O}_{3}$ nanoparticles. Biochem. Eng. J., 43: 303-306.

Jigneshkumar, V. Rohit, Jignasa, N. Solanki and Suresh Kumar, Kailasa, 2014. Surface modification of silver nanoparticles with dopamine dithiocarbamate for selective colorimetric sensing of mancozeb in environmental samples. Sensors and Actuators B: Chemical, 200: 219-226.

Kamle, M., Kumar, P., Gupta, V. K., Tiwari, A. K., Misra, A. K. and Pandey, B. K. 2013. Identification and phylogenetic correlation among Colletotrichum gloeosporioides pathogen of anthracnose for mango. Biocat. Agric. Biotechnol., 2(3): 285-287.

Kamle, Madhu and Pradeep Kumar 2016. Colletotrichum gloeosporioides: Pathogen of anthracnose disease in mango (Mangifera indica L.). In: Kumar, P., Gupta, V., Tiwari, A. and Kamle, M. (eds.) Current Trends in Plant Disease Diagnostics and Management Practices, Fungal Biology, Springer, Cham, pp. 207-219.

Kumar, V. and Yadav, S. K. 2009. Plant-mediated synthesis of silver and gold nano-particles and their applications. J. Chem. Technol. Biotechnol., 84: 151-157.

Lee, K.J., Park, S.H., Govarthanan, M., Hwang, P.H., Seo, Y.S., Cho, M., Lee, W.H., Lee, J.Y., Kamala-Kannan, S. and Oh, B.T. 2013. Synthesis of silver nanoparticles using cow milk and their antifungal activity against phytopathogens. Mater Lett., 105: 128-131.

Liang, F. H., Yong, G. X., Yuan Z. Z., and Min, M. A. 2010. Study on the crystalline structure and thermal stability of silver oxide films deposited by direct-current reactive magnetron sputtering methods. J. Korean Phys. Soc., 56: 1176-1179.

Neglia, G., Balestrieri, A., Gasparrini, B., Cutrignelli, M.I., Bifulco, G., Salzano, A., Cimmino, R., Varricchio, E., D'Occhio, M.J. and Campanile, G. 2014. Nitrogen and phosphorus utilization and excretion in dairy buffalo intensive breeding. Italian Journal of Animal Science, 13(4): 3362.

Pathak, M. L. and Kumar, A. 2003. Cow praising and importance of Panchyagavya as medicine. Sachitra Ayurveda, 5: 569.

Pradhan, S.S., Verma, S., Kumari, S. and Singh, Y. 2018. Bio-efficacy of cow urine on crop production: A review. International Journal of Chemical Studies, 6(3): 298-301.

Prakash, O., Misra, A. K. and Kishun, R. 1997. Some threatening diseases of mango and their management. In: Agnihotri, V. P., Sarbhoy, A. K., and Singh, D. V. (eds.), Management of Threatening Plant Diseases, $\left(1^{\text {st }}\right.$ edn). Malhotra Publishing House, New Delhi, pp.179 -205.

Raghavendra, S. N., Raghu, H. S., Divyashree, K. and Rajeshwara, A. N. 2019. Antifungal efficiency of copper oxychloride (coc) conjugated silver nanoparticles against Colletotrichum gloeosporioides which causes anthracnose disease. Asian J. Pharm. Clin. Res., 12(8): 230-233.

Raghu, V. 2015. Study of dung, urine and milk of selected grazing animals as bioindicators in environmental geoscience - A case study from Mangampeta barite mining area, Kadapa District, Andhra Pradesh, India. Environ. Monit. Assess., 187: 4080.

Sahu, R. K., Krishnaiah, N., Ramya, P. and Anusha, P. 2016. Cow urine- therapeutic value. International Journal of Livestock Research, 6(11): 93-99.

Sastry, M., Mayya, K. S. and Bandyopadhyay, K. 1997. pH dependent changes in the optical properties of carboxylic acid derivatized silver colloidal particles. Colloids Surf A, 127: 221-228.

Sastry, M., Patil, V. and Sainkar, S. R. 1998. Electrostatically controlled diffusion of carboxylic acid derivatized silver colloidal particles in thermally evaporated fatty amine films. Phys. Chem. B, 102: 1404-1410.

Sayiprathap, B. R., Ekabote, S. D., Nagarajappa Adivappar, Narayanaswamy, H. and Ravindra, H. 2018. Screening of fungicides against anthracnose disease of mango on nursery seedlings. International Journal of Chemical Studies, 6(4): 1494-1497.

Shahverdi, A. R., Minaeian, S., Shahverdi, H. R., Jamalifar, H. and Nohi A. 2007. Rapid synthesis of silver nanoparticles using culture supernatants of Enterobacteria: A novel biological approach. Process Biochem., 42: 919-923.

Shourbagy, M. R. and Abdel Monem Ahmed 1953. A study of bovine urine in health and disease. The British Veterinary Journal, 109(7): 296-298.

Thakur, A. N. 2004. Therapeutic use of urine in early Indian medicine. Indian Journal of History of Science, 39(4): 415-427.

Vaibhav, T., Rajesh, N., Vijay, P., Ajay, P. S., Debashis, R., Ambika, S., Pawanjit, S. and Abhishek, P. 2018. Evaluation of in vitro anti-microbial activity of goat urine peptides. Journal of Animal Research, 8: 33-37.

Velmurugan, P., Shim, J., Kamala Kannan, S., Lee, K.J., Oh, B.T., Balachandar, V. and Oh, B.T. 2011. Crystallization of silver through reduction process using Elaeis guineensis biosolid extract. Biotechnol Prog., 27(1): 273-279.

Venugopal, N. V. S. and Sainadh, N. V. S. 2016. Novel polymeric nanoformulation of Mancozeb - An eco-friendly nanomaterial. International Journal of Nanoscience, 15(3): 1650016 